\title{
Transactivation Properties of Wild-Type and Mutant Androgen Receptors in Transiently Transfected Primary Human Fibroblasts
}

\author{
P.M. Holterhus J. Salzburg R. Werner O. Hiort \\ Department of Pediatrics, University Hospital Schleswig Holstein, Campus Lübeck, Lübeck, Germany
}

\section{Key Words}

Androgen receptor - Androgen insensitivity syndrome •

Fibroblasts · Transactivation - Transfection

\begin{abstract}
Background: Stromal cells play key roles during androgen-mediated male sexual differentiation. Our objective was to establish a transient transfection method for primary human fibroblasts enabling functional characterization of wild-type (wt) and mutant androgen receptor (AR) plasmid constructs, corresponding to partial and complete androgen insensitivity syndrome (PAIS/CAIS). Methods: An AR-negative fibroblast strain (ARD842) was established from the gonads of a CAIS patient. Wt-AR or either mutants L712F (PAIS), R774C or V866M (CAIS) were transfected using a polyamine-based procedure. Alternatively, two AR-positive male foreskin fibroblast strains were investigated. Androgen-induced activation of two co-transfected reporter plasmids ((ARE) ${ }_{2}$ TATA-, MMTV-luciferase) was measured. Results: All three fibroblast strains showed a ligand-dependent rise of luciferase activity after transfection of wt-AR. Mutant plasmids were assessed in AR-negative ARD842 cells. While L712F showed high partial activity, R774C and V866M
\end{abstract}

This work is part of the Medical Thesis of Janina Salzburg.

\section{KARGER}

Fax +4161306 1234 E-Mail karger@karger.ch www.karger.com

\section{(C) 2005 S. Karger AG, Basel}

0301-0163/05/0633-0152\$22.00/0

Accessible online at:

www.karger.com/hre were nearly inactive. The intrinsic AR of normal foreskin fibroblasts revealed no measurable ligand-inducible reporter gene activity. Conclusions: Polyamine-based transfection of AR plasmids into cultured fibroblasts provides a promising tool for analysis of $A R$ transactivation, thereby considering a stromal cellular background. This is supported by the mutant ARs which showed the expected levels of impaired transactivation with respect to the corresponding AIS phenotypes. The role of the intrinsic $A R$ in normal male human foreskin fibroblasts needs further exploration.

Copyright (C) 2005 S. Karger AG, Basel

\section{Introduction}

Male sexual differentiation is dependent on normal action of androgens via the androgen receptor (AR). During the initial steps of androgen-dependent morphogenesis, urogenital mesenchymal cells represent the crucial androgen target tissue [1,2]. Mutations of the X-chromosomal AR gene cause functional impairment of the AR and therefore lead to defective virilization in genetically male individuals, termed androgen insensitivity syndrome (AIS). The phenotype of AIS comprises a wide clinical spectrum ranging from individuals with completely female external genitalia (complete AIS = CAIS) over different forms with genital ambiguity to phenotyp- 
ically normal males with only slight undervirilization and/or infertility (partial AIS = PAIS) [3, 4].

The pathogenic relevance of AR gene mutations in AIS has generally been confirmed by transient transfection assays examining transactivation of androgen-inducible reporter genes. Usually, fast-growing, non-human, nonmesenchymal, immortalized cell lines have been used for these studies [5-9]. Interestingly, in some published reports in vitro function of the AR and the genital phenotype of the corresponding AIS patients have not always correlated satisfactorily. In a few cases, distinct mutations of the AR gene have been associated with complete absence of in vivo function of the AR (CAIS) but still have revealed a considerable level of partial activity in transactivation studies employing Chinese hamster ovary (CHO) - or other mammalian cells [10-14]. There is increasing experimental evidence that AR-mediated activation of target gene transcription is a cell type-specific process embedded in a complex tissue-specific network of co-activators and co-repressors [15-17]. These considerations stimulated us to study AR function in a human fibroblast-based AR transactivation model.

\section{Materials and Methods}

The study has been approved by the Ethical Committee of the University of Lübeck, Germany.

\section{Plasmids}

The wild-type (wt) AR expression plasmid pSVAR0 was obtained from A.O. Brinkmann, Erasmus University (Rotterdam, The Netherlands) [18]. Mutant AR expression plasmids were selected based on availability of functional experimental data in previous reports by ourselves and also by others. R774C (pSVAR$\mathrm{R} 774 \mathrm{C}$ ) represents a mutation with an expected complete absence of AR activity in vitro based on classical reporter gene assays in different laboratories including ours $[5,19]$. The L712F (pSVARL712F)-mutated AR has been associated with PAIS and male phenotype and was selected because of its high partial reporter gene activity in CHO cells using the identical plasmid in our own laboratory [9]. The V866M mutation (pSVAR-V866M) served as model for a mutation with considerable partial in vitro activity in fastgrowing cell lines despite its usual association with CAIS [11, 12]. Generation of the AR expression plasmids and their verification has previously been reported in detail $[9,19,20]$.

Two structurally different androgen-responsive luciferase reporter genes have been used as a model emulating potential differences occurring in the promoter regions of natural androgen-responsive target genes. MMTV-luciferase contained the well-characterized androgen-responsive mouse mammary tumor virus promoter [21] and was obtained from Organon (West Orange, N.J., USA). The (ARE) 2 TATA-luciferase reporter plasmid was a gift from G. Jenster, Department of Pathology, Erasmus University (Rotterdam, The Netherlands) [22]. To monitor transfection effi- ciency, a constitutively expressed Renilla luciferase plasmid (pRLSV40) was co-transfected which was obtained from Promega Corp. (Madison, Wisc., USA). The empty plasmid pTZ19 has been documented to behave neutrally with respect to transcriptional regulation by AR $[9,19,20]$ and was included to adjust for constant DNA concentrations in transfection mixtures containing no AR plasmid.

\section{Cell Strains}

The ARD842 fibroblast strain has been established from a gonadal biopsy during gonadectomy in a CAIS patient. The underlying mutation of the AR gene, a 26-base pair deletion in exon 1 (codons 141-150), caused a frameshift in the open reading frame predicting for a premature stop codon. This has been supported by ligand-binding analyses showing absent androgen binding in ARD842 cells [15]. In addition, two fibroblast strains derived from the foreskin of a prepubertal (nGSF58) and a postpubertal normal male (nGSF56), respectively, were cultivated. These two fibroblast strains showed normal androgen binding [15]. Genome-wide gene expression analyses using 44,000 spot cDNA microarrays confirmed the biological identity of the established three cell strains by cluster analyses indicating characteristic gonadal (ARD842) and foreskin (nGSF58, nGSF56) gene expression phenotypes, respectively [15]. The fibroblasts were maintained at $5 \% \mathrm{CO}_{2}$ at $37^{\circ} \mathrm{C}$ in DMEM with the nutrient mix F-12 (DMEM/F12, Life Technologies, Inc., Grand Island, N.Y., USA), 10\% (vol/vol) fetal calf serum (FCS), 1\% (vol/vol) MEM non-essential amino acids (Life Technologies, Inc.) and penicillin $(200 \mathrm{IU} / \mathrm{ml}) /$ streptomycin $(0.2 \mathrm{mg} /$ $\mathrm{ml})$. For the transactivation studies, steroid-free FCS has been used.

Transient Transfections and Reporter Gene Assays

Transient transfections of fibroblasts were performed using the Gene Jammer polyamine transfection reagent from Stratagene (La Jolla, Calif., USA) mainly according to the instructions provided by the manufacturer. However, several specific modifications had to be included. More than 70-fold ligand-induced luciferase activity over baseline was achieved under these optimized conditions. In detail, 6th passage fibroblasts were precultivated to confluence which they reached in $175-\mathrm{cm}^{2}$ culture flasks after approximately 10-14 days resulting in the $\mathrm{G}_{0}$ cell cycle state [15]. Cells were then washed twice with phosphate-buffered saline ( $\mathrm{pH} 7.4)$, trypsinized, and seeded on $10-\mathrm{cm}^{2} 6$-well multidishes using $2.5 \mathrm{ml}$ steroid-free culture media containing 300,000 fibroblasts/well. To prepare the transfection mixture, $100 \mu \mathrm{l} /$ well of sterile, serum-free and antibiotic-free DMEM/F12 at room temperature were transferred into a polystyrene tube. Subsequently, $12 \mu$ l of Gene Jammer transfection reagent were added followed by a 10 -min incubation time. Then, $1 \mu \mathrm{g} /$ well of either wt-AR or mutant AR expression plasmids or the carrier plasmid, $1 \mu \mathrm{g} /$ well of either $\mathrm{ARE}_{2} \mathrm{TATA}$-luciferase or MMTV-luciferase reporter genes and $15 \mathrm{ng} /$ well of pRLSV40 were added followed by another 10-min incubation time. Subsequently, culture media was removed from the 6-well multidishes and replaced by $900 \mu 1 /$ well of fresh DMEM/F12 with $10 \%$ steroid-free FCS without antibiotics. Then, $100 \mu \mathrm{l} /$ well of the transfection mixture were added dropwise to each well. After $3 \mathrm{~h}, 1 \mathrm{ml} /$ well of DMEM/F12 with $10 \%$ steroid-free and antibiotic-free FCS were added. $24 \mathrm{~h}$ later, cells were washed twice with phosphate-buffered saline and incubated with steroid-free culture media containing either ethanol or 0.001-100 nM methyltrienolone (R1881) or di- 
Fig. 1. Western immunoblot analyses of transiently transfected cell line ARD842. Lane 1 = ARD842, pSVAR0; lane 2 = ARD842, carrier plasmid; lane 3=ARD842, not transfected; lane 4 = ARD842, pSVARR774C; lane 5 = ARD842, pSVAR-L712F; lane $6=$ ARD842, pSVAR-V866M. Upper panel $=$ immunodetection of the AR; lower panel $=$ immunodetection of actin.

Fig. 2. Western immunoblot analyses of transiently transfected cell lines nGSF56 and nGSF58. Lane 1 = nGSF56, pTZ19; lane 2 = nGSF56, pSVAR0; lane $3=$ nGSF58, pTZ19; lane $4=$ nGSF58, pSVAR0. Upper panel = immunodetection of the AR; lower panel = immunodetection of actin.
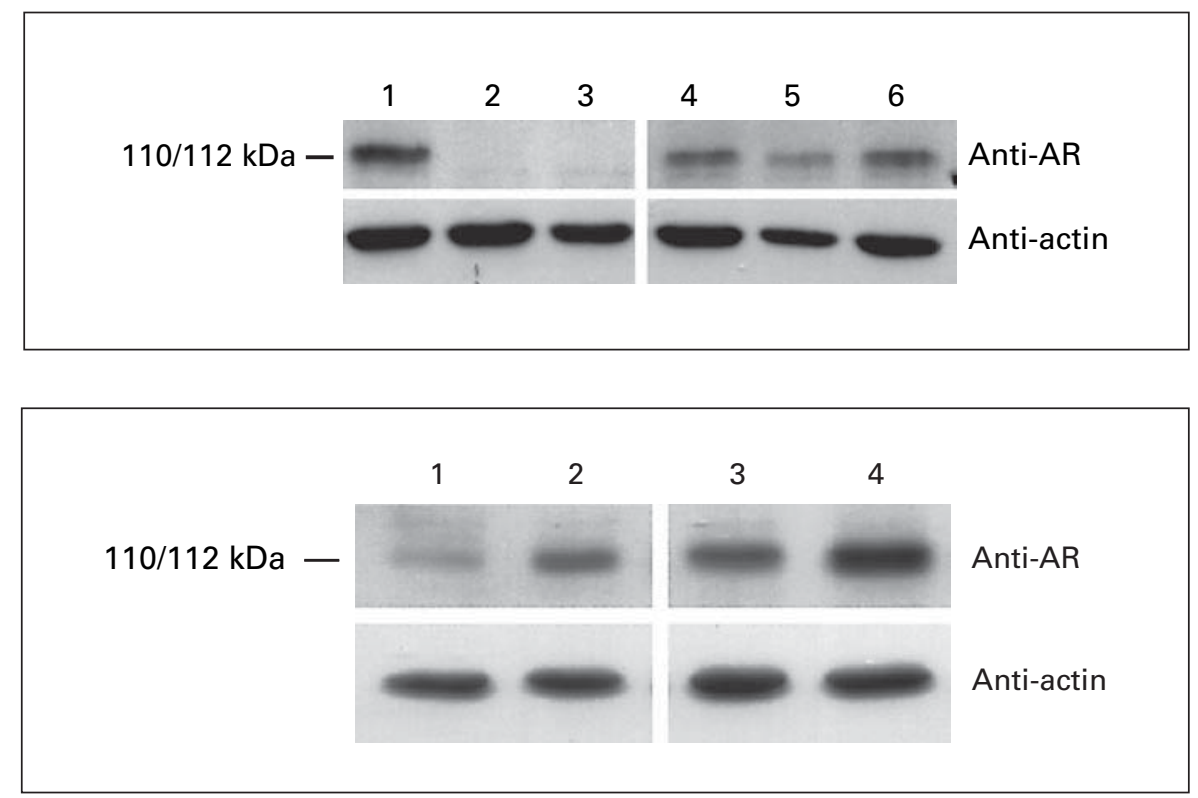

hydrotestosterone (DHT). Activation of the androgen-responsive luciferase genes as well as the constitutively expressed Renilla luciferase gene was measured using the dual luciferase reporter gene assay (Promega Corp.). All experiments were performed in triplicate. Three independent triplicate experiments were performed on 3 different days. To compare experiments performed on different days, relative luciferase units have been set equal to 1 for wt-AR activity in response to $10 \mathrm{n} M$ of respective androgen. Relative luciferase units due to activation of the wt-AR by other androgen concentrations in the same experiment and relative luciferase units due to any other AR plasmid construct in response to any hormone concentration studied in the same experiment have been expressed relative to this value. The mean and SD of the three independent experiments were calculated.

\section{Western Immunoblot Analysis}

Western immunoblot analyses were performed as described earlier [23]. In brief, cells were cultured in $175-\mathrm{cm}^{2}$ culture flasks at the same density and conditions as described for 6-well multidishes used for transactivation studies. AR protein expression in the ARD842 fibroblasts was studied either without prior transfection or following transient transfection of the mutant AR constructs pSVAR-R774C, pSVAR-L712F, and pSVAR-V866M as well as the wt-AR construct pSVAR0. Furthermore, the two normal foreskin fibroblast strains were transfected using either the carrier plasmid pTZ19 alone or additional pSVAR0. The monoclonal anti-AR antibody F34.9.1 (InnoGenex, Inc., San Ramon, Calif., USA) was used for AR protein detection. For means of comparability of AR protein expression levels, specific immunostaining of the housekeeping gene actin was performed.

\section{Results}

\section{AR Expression Studies}

As expected from the molecular genetic alteration of the AR gene, protein lysates of the non-transfected ARnegative cell strain ARD842 revealed no AR-specific signal using the anti-AR antibody F39.4.1 (fig. 1, lane 3). The same was true after sole transfection of pTZ19 (fig. 1, lane 2). However, following transient transfection of pSVAR0, a specific band at 110/112 kDa appeared, clearly indicating the expression of the wt-AR in the ARD842 cells (fig. 1, lane 1). Transient transfection of pSVARR774C, pSVAR-L712F, and pSVAR-V866M also resulted in well-detectable expression of the AR protein.

Expectedly, protein lysates of both normal foreskin fibroblast strains nGSF56 and nGSF58 showed clear ARspecific immunostaining at $110 / 112 \mathrm{kDa}$ in immunoblots already after transfection of pTZ19 alone (fig. 2, lanes 1 and 3). The lower signal in nGSF56 compared with nGSF5 8 (fig. 2, lane 1 vs. lane 3) reflected the lower maximum ligand binding in nGSF56 [15]. Upon transfection of pSVAR0, a clear rise of signal intensity of the AR-specific bands was detectable in both fibroblast strains indicating overexpression of the AR (fig. 2, lane 2 vs. lane 1 and lane 4 vs. lane 3 ).

\section{Transactivation Analyses}

Using the wt-AR expression plasmid pSVAR0, we detected a concentration-dependent activation of the 


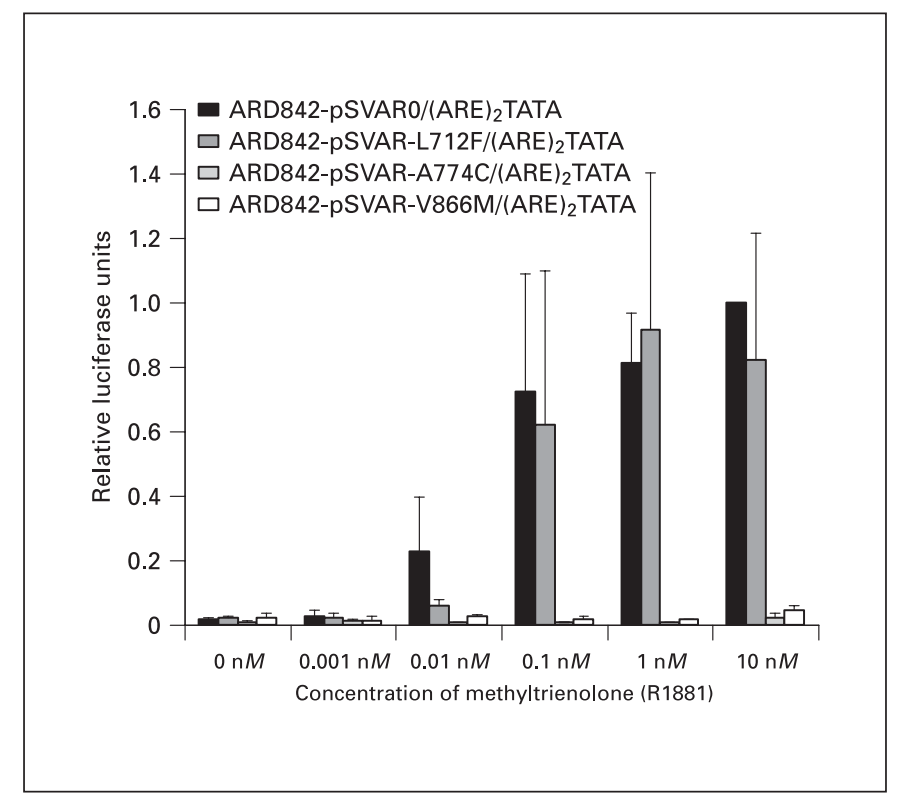

Fig. 3. Transactivation of (ARE) $)_{2}$ TATA-luc due to pSVAR0, pSVAR-L712F, pSVAR-R774C, and pSVAR-V866M in response to increasing concentration of R1881 (methyltrienolone) using ARD846 fibroblasts. y-axis: relative luciferase units (RLU). RLU due to pSVAR0 using $10 \mathrm{n} M$ R1881 was defined to be 1 . All other experiments were expressed relative to this value. $\mathrm{x}$-axis $=\mathrm{R} 1881$ concentration, error bars $+1 \mathrm{SD}$.

$(\mathrm{ARE})_{2}$ TATA-luciferase reporter gene in the ARD842 fibroblasts in response to the stable androgen analogue R1881, indicating that the transfected AR was not only expressed on the protein level but was also functionally active as a transcriptional regulator within these cells under the established transfection conditions (fig. 3). In negative control experiments, transfections of the reporter gene alone did not reveal ligand-inducible luciferase activity indicating AR specificity of the results (data not shown). In addition, we analyzed the mutant constructs pSVAR-L712F, pSVAR-R774C and pSVAR-V866M. While pSVAR-R774C was completely inactive, pSVARL712F revealed high partial activity reaching the wt-AR activation level at 0.1-10 $\mathrm{n} M \mathrm{R} 1881$. As observed for pSVAR-R774C, pSVAR-V866M did not show any relevant transcriptional activity in ARD842 up to concentrations of $10 \mathrm{n} M \mathrm{R} 1881$ either (fig. 3).

In further experiments, we analyzed the transactivation properties of the pSVAR-V866M construct in comparison with pSVAR0 in ARD842 cells using the natural ligand DHT. At concentrations ranging from 0.001 to $10 \mathrm{n} M$, pSVAR-V866M was almost inactive again. This

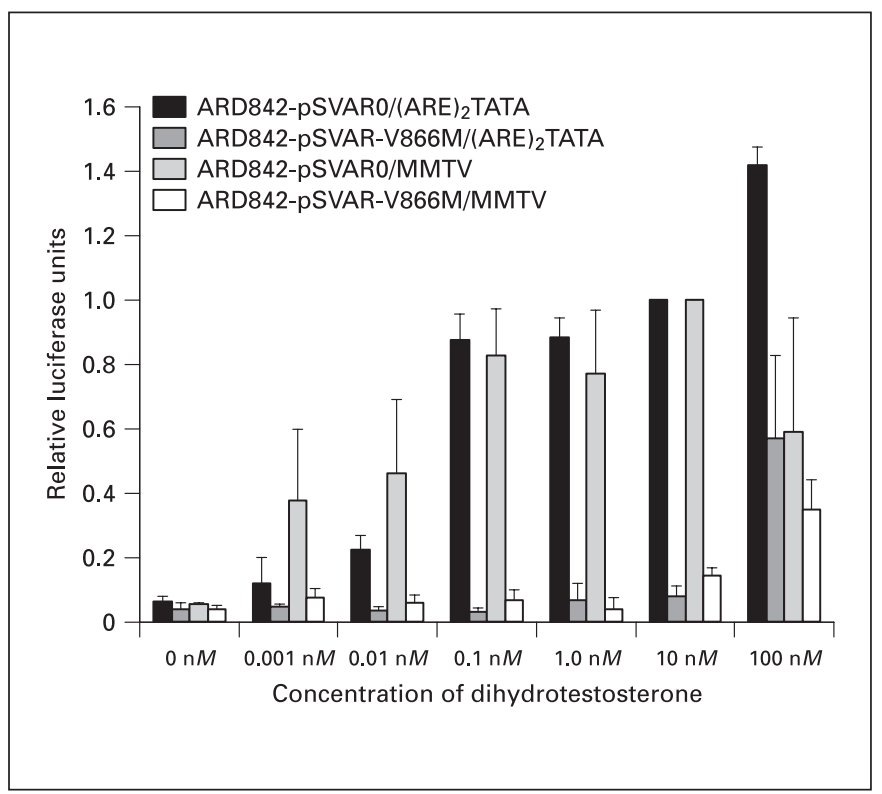

Fig. 4. Transactivation of (ARE) $)_{2}$ TATA-luc and MMTV-luc, respectively, due to pSVAR0, and pSVAR-V866M in response to increasing concentration of DHT (dihydrotestosterone) using ARD846 fibroblasts. y-axis: relative luciferase units (RLU). RLU due to pSVAR0 using $10 \mathrm{n} M$ DHT was defined to be 1 for either promoter. All other experiments with the same promoter were expressed relative to this value. $\mathrm{x}$-axis $=\mathrm{DHT}$ concentration, error bars $+1 \mathrm{SD}$

result was independent from using either minimal (ARE) $)_{2}$ TATA-luciferase reporter gene or the complex MMTV-luciferase reporter gene (fig. 4). Only at $100 \mathrm{n} M$ DHT, a pharmacological concentration far above physiological levels, partial reporter gene activation due to pSVAR-V866M occurred (fig. 4). Decreasing activity due to wt-AR activating the MMTV-luciferase reporter gene at $100 \mathrm{n} M$ DHT compared with $10 \mathrm{n} M$ DHT (fig. 4) was attributed to squelching occurring at high hormone concentrations under the chosen transfection conditions.

As in ARD842 fibroblasts, the foreskin fibroblasts nGSF56 showed a clear concentration-dependent induction of luciferase activity following transient co-transfection of pSVAR0 and the (ARE) 2 TATA-luciferase reporter gene (fig. 5). However, after transfection of the (ARE) $)_{2}$ TATA-luciferase reporter gene without an AR expression plasmid, no hormone-dependent induction of luciferase activity occurred. We observed the same results when we performed the experiment in the nGSF58 cell line and when we used an MMTV-luciferase reporter gene instead of the (ARE) $)_{2}$ TATA-luciferase reporter gene, respectively (data not shown). 


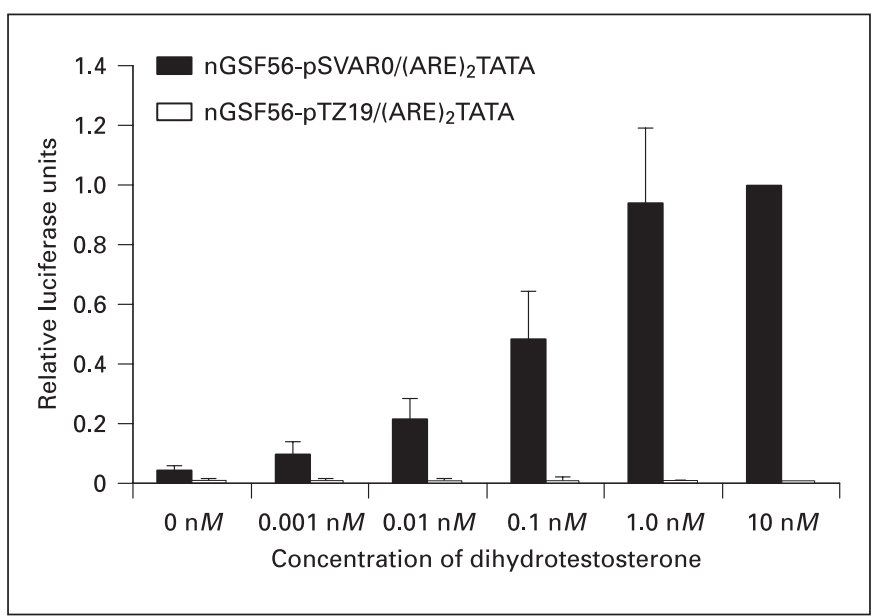

Fig. 5. Transactivation of (ARE) $)_{2}$ TATA-luc due to pSVAR0 in response to increasing concentration of DHT (dihydrotestosterone) using nGSF56 fibroblasts. y-axis: relative luciferase units (RLU). RLU due to pSVAR0 using $10 \mathrm{n} M$ DHT was defined to be 1 . All other experiments were expressed relative to this value. $\mathrm{x}$-axis $=$ DHT concentration, error bars $+1 \mathrm{SD}$.

\section{Discussion}

Our data indicate that transient transfection of the wtAR expression plasmid pSVAR0 into AR-negative ARD842 fibroblasts using a polyamine-based transfection procedure results in expression of the AR protein. In normal male foreskin fibroblasts, transfection of AR results in a relative overexpression of the AR compared with baseline conditions. Our data prove that the transfected AR is functionally active with respect to androgeninduced transactivation of two different androgen-responsive reporter genes, (ARE) $)_{2}$ TATA-luciferase and MMTV-luciferase, using two different androgens, DHT and R1881, respectively. In conclusion, transfected ARD842 and transfected normal foreskin fibroblasts both provide an intracellular environment harboring the necessary components to enable the AR transactivation cascade.

AR transactivation has not been consistently observed in experiments with cultured fibroblasts in the published literature suggesting particular significance of the underlying experimental conditions [15, 24-28]. In a previous study, we showed the lack of a reproducible transcriptional response pattern to androgen treatment in cultured AR-positive normal male foreskin fibroblasts under various experimental conditions using a microarray-based approach [15]. Our present data on transfected normal male foreskin fibroblasts with documented AR expression confirm these findings by limiting reporter gene activation to those experiments with co-transfection of AR plasmids resulting in overexpression of AR.

Bamberger et al. [29] have published a very similar experimental phenomenon of glucocorticoid receptor function in untransfected versus transfected human lymphocytes. Interestingly, an even more equivalent observation compared with our study has very recently been published by Castoria et al. [27] using NIH3T3 mouse fibroblasts. The authors could not demonstrate AR transactivation due to the intrinsic murine AR. However, the receptor showed nuclear translocation and transcriptional activity following AR transfection. Interestingly, the intrinsic AR showed ligand-dependent activation of other signaling pathways than AR transactivation in the experiments performed by Castoria et al. [27]. The authors of that study concluded that the observed functional diversity of the AR was mainly due to differences in AR expression levels of untransfected versus transfected NIH3T3 cells. Our data support these conclusions by demonstrating a clear rise in AR-specific signal intensity in Western immunoblots following transfection of normal foreskin fibroblasts with the wt-AR plasmid pSVAR0.

In order to have defined experimental conditions avoiding potential interferences between the intrinsic AR of the normal foreskin fibroblasts and the transfected AR via cross-talk of signaling pathways, we decided to restrict the analyses of the AR mutants to the AR-negative ARD842 fibroblast cell line. While these cells provide the cellular characteristics of stromal cells, they do not originate from the androgen-responsive anatomic region of the external genitalia. This could be of significant potential disadvantage for distinct AR mutants because the difference between gonadal versus foreskin fibroblasts is reflected by a significant and wide-ranging divergence in the cellular gene expression phenotypes [15]. However, as all tested AR plasmids showed the expected levels of impaired transactivation with respect to the corresponding AIS phenotypes, this was of no obvious relevance for the selected mutations in our present study.

For fibroblast transfections, we have used the identical AR plasmid constructs which we have previously studied in our own laboratory on transiently transfected $\mathrm{CHO}$ cells using the same reporter plasmids. The high partial activity due to pSVAR-L712F in transfected fibroblasts of the present study is well in accordance with our data on L712F AR function in CHO cells [9], thus both reflecting the corresponding PAIS phenotype with predomi- 
nantly male external genitalia. Likewise, the expected complete absence of transactivation function due to pSVAR-R774C in transfected ARD842 fibroblasts matched well with functional data obtained earlier in $\mathrm{CHO}$ cells [19], thus corresponding again with the underlying phenotype (CAIS) [5]. These data indicate that functional impairment of the AR due to the tested mutations in the AR gene is reflected conclusively in transfected ARD842 fibroblasts and confirms previous data.

The V866M mutant was of particular interest in our study. This mutant AR has usually been associated with the CAIS phenotype in the literature $[11,12,30,31]$. Ahmed et al. [31] reported 3 different individuals with CAIS having this mutation. We ourselves care for 2 unrelated individuals with this mutation. While 1 patient showed the expected CAIS phenotype (data not shown), the second individual was significantly virilized. In the latter, we have proven that this unexpected partial virilization was not due to activity of the V866M mutant AR itself but instead due to wt-AR expression caused by somatic mosaicism of mutant and wt-AR genes due to a post-zygotic mutation [20]. McPhaul et al. [32] reported a single case in which they described the phenotype as 'incomplete testicular feminization' suggesting at least limited partial virilization. Somatic mosaicism has not been excluded in that patient. Therefore, with the only exception of the subject presented by McPhaul et al., V866M seems usually not to be associated with relevant in vivo androgen action.

In contrast to these in vivo observations, the V866Mmutated AR always showed partial reporter gene activation up to two-thirds of wt-AR activity in our own hands using the same plasmid on CHO cells [20]. Similar observations on partial activity due to V866M mutant AR have been reported by two independent groups $[11,12]$. Several further examples of AR mutants associated with CAIS but demonstrating significant activity in vitro have been published, e.g., L907F [10], R831Q [13], R855H [14]. It has been suggested that residual activity of AR mutants corresponding to CAIS may be associated with the development of Wolffian ducts thus reflecting to some extend the internal genital phenotype [33]. Interestingly, the V866M mutation almost completely abolished AR function in the transfected fibroblasts no matter which reporter gene has been used. Therefore, in case of V866M, the presented transactivation data seemed to provide a more conclusive representation of the external genital CAIS phenotype.

Experimental variations of transfection procedures compromise the comparability of AR transactivation data among different laboratories and even within the same institution using different cell types because different cell types need different optimal transfection conditions. Because we only achieved consistent and successful AR transactivation in fibroblasts after specific optimization of the experimental protocol and because of obvious differences in the proliferative behavior of $\mathrm{CHO}$ cells versus fibroblasts, we did not directly apply fibroblast transfection conditions on $\mathrm{CHO}$ cells. On the other hand, fibroblasts were not transfectable using conditions developed for CHO cells. Nevertheless, it cannot be excluded that certain variations in transfection procedures of $\mathrm{CHO}$ cells could also lead to improved exposure of functional defects due to specific AR mutations.

The cell type is likely to play a significant role with respect to AR transactivation [15-17]. We believe that part of the considerably low activity of the V866M-mutated AR in the present study is based on the specific intracellular environment provided by the used stromal cells. These considerations make polyamine-based transiently transfected fibroblasts a promising additional model for future studies of distinct mutations of the AR gene in AIS.

\section{Acknowledgements}

The study was funded by the Deutsche Forschungsgemeinschaft (DFG) grant KFO-111/1-1 and 1-2 and by the Friedrich Bluhme and Else Jebsen Foundation, Lübeck, Germany, to P.M.H. and to O.H. P.M.H. received a research stipend by the Novartis Foundation, Germany. The authors thank C. Marschke, C. Havel, N. Homburg, and D. Struve for excellent technical assistance. Several plasmids were generous gifts by A.O. Brinkmann and G. Jenster (both Erasmus University, Rotterdam, The Netherlands). 


\section{References}

1 Hiort O, Holterhus PM: The molecular basis of male sexual differentiation. Eur J Endocrinol 2000; 142:101-110.

-2 Cunha GR, Chung LWK, Shannon JM, Reese BA: Stromal-epithelial interactions in sex differentiation. Biol Reprod 1980;22:19-42.

$\checkmark 3$ Patterson MN, McPhaul MJ, Hughes IA: Androgen insensitivity syndrome. Baillieres Clin Endocrinol Metab 1994;8:379-404.

$\checkmark 4$ Quigley CA, De Bellis A, Marschke KB, elAwady MK, Wilson EM, French FS: Androgen receptor defects: Historical, clinical, and molecular perspectives. Endocr Rev 1995;16: 271-321.

5 Marcelli M, Tilley WD, Zoppi S, Griffin JE, Wilson JD, McPhaul MJ: Androgen resistance associated with a mutation of the androgen receptor at amino acid 772 (Arg $\rightarrow$ Cys) results from a combination of decreased messenger ribonucleic acid levels and impairment of receptor function. J Clin Endocrinol Metab 1991;73: 318-325.

-6 Lobaccaro JM, Lumbroso S, Poujol N, Georget V, Brinkmann AO, Malpuech G, Sultan C: Complete androgen insensitivity syndrome due to a new frameshift deletion in exon 4 of the androgen receptor gene: Functional analysis of the mutant receptor. Mol Cell Endocrinol 1995;111:21-28.

7 Shkolny DL, Beitel LK, Ginsberg J, Pekeles G, Arbour L, Pinsky L, Trifiro MA: Discordant measures of androgen-binding kinetics in two mutant androgen receptors causing mild or partial androgen insensitivity, respectively. J Clin Endocrinol Metab 1999;84:805-810.

$\checkmark 8$ Ris-Stalpers C, Kuiper GG, Faber PW, Schweikert HU, van Rooij HC, Zegers ND, Hodgins MB, Degenhart HJ, Trapman J, Brinkmann AO: Aberrant splicing of androgen receptor mRNA results in synthesis of a nonfunctional receptor protein in a patient with androgen insensitivity. Proc Natl Acad Sci USA 1990;87:7866-7870.

$\checkmark 9$ Holterhus PM, Sinnecker GH, Hiort O: Phenotypic diversity and testosterone-induced normalization of mutant L712F androgen receptor function in a kindred with androgen insensitivity. J Clin Endocrinol Metab 2000;85: 3245-3250.

10 Bevan CL, Hughes IA, Patterson MN: Wide variation in androgen receptor dysfunction in complete androgen insensitivity syndrome. J Steroid Biochem Mol Biol 1997;61:19-26.

$\checkmark 11$ Brown TR, Lubahn DB, Wilson EM, French FS, Migeon CJ, Corden JL: Functional characterization of naturally occurring mutant androgen receptors from subjects with complete androgen insensitivity. Mol Endocrinol 1990;4: 1759-1772.

$\checkmark 12$ Kazemi-Esfarjani P, Beitel LK, Trifiro M, Kaufman M, Rennie P, Sheppard P, Matusik R, Pinsky L: Substitution of valine- 865 by methionine or leucine in the human androgen receptor causes complete or partial androgen insensitivity, respectively with distinct androgen receptor phenotypes. Mol Endocrinol 1993;7: 37-46.
13 Shkolny DL, Brown TR, Punnett HH, Kaufmann M, Trifiro MA, Pinsky L: Characterization of amino acid substitutions at arginine- 830 of the androgen receptor that cause complete androgen insensitivity in three families. Hum Mol Genet 1995;4:515-521.

14 Marcelli M, Zoppi S, Wilson C, Griffin J, McPhaul M: Amino acid substitutions in the hormone binding domain of the human androgen receptor alter the stability of the hormone receptor complex. J Clin Invest 1994;94:16421650 .

15 Holterhus PM, Hiort O, Demeter J, Brown PO, Brooks JD: Differential gene expression patterns in genital fibroblasts of normal males and 46,XY females with androgen insensitivity syndrome: Evidence for early programming involving the androgen receptor. Genome Biol 2003;4:R37.1-37.10.

16 DePrimo SE, Diehn M, Nelson JB, Reiter RE, Matese J, Fero M, Tibshirani R, Brown PO, Brooks JD: Transcriptional programs activated by exposure of human prostate cancer cells to androgen. Genome Biol 2002;3:R32.132.12 .

17 Heinlein SA, Chang C: Androgen receptor coregulators: An overview. Endocr Rev 2002;23: 175-200.

18 Brinkmann AO, Faber PW, van Rooij HC, Kuiper GG, Ris C, Klaassen P van der Korput JA, Voorhorst MM, van Laar JH, Mulder E, Trapmann J: The human androgen receptor: Domain structure, genomic organization and regulation of expression. J Steroid Biochem 1989;34:307-310.

19 Holterhus PM, Wiebel J, Sinnecker GH, Brüggenwirth HT, Sippell WG, Brinkmann AO, Kruse K, Hiort O: Clinical and molecular spectrum of somatic mosaicism in androgen insensitivity syndrome. Pediatr Res 1999;46: 684-690.

20 Holterhus PM, Sinnecker GH, Wollmann HA, Struve D, Homburg N, Kruse K, Hiort O: Expression of two functionally different androgen receptors in a patient with androgen insensitivity. Eur J Pediatr 1999; 158:702-706.

21 Truss M, Beato M: Steroid hormone receptors: Interaction with deoxyribonucleic acid and transcription factors. Endocr Rev 1993;14: 459-479.

22 Jenster G, Spencer TE, Burcin MM, Tsai SY, Tsai MJ, O’Malley BW: Steroid receptor induction of gene transcription: A two-step model. Proc Natl Acad Sci USA 1997;94:78797884.

23 Holterhus PM, Brüggenwirth HT, Hiort O, Kleinkauf-Houcken A, Kruse K, Sinnecker GH, Brinkmann AO: Mosaicism due to a somatic mutation of the androgen receptor gene determines phenotype in androgen insensitivity syndrome. J Clin Endocrinol Metab 1997; 82:3584-3589.
24 Elmlinger MW, Mayer I, Schnabel D, Schuett BS, Diesing D, Romalo G, Wollmann HA, Weidemann W, Spindler KD, Ranke MB, Schweikert HU: Decreased expression of IGFII and its binding protein, IGF-binding protein-2, in genital skin fibroblasts of patients with complete androgen insensitivity syndrome compared with normally virilized males. J Clin Endocrinol Metab 2001;86: 4741-4746.

25 Hellwinkel OJ, Bassler J, Hiort O: Transcription of androgen receptor and $5 \alpha$-reductase II in genital fibroblasts from patients with androgen insensitivity syndrome. J Steroid Biochem Mol Biol 2000; 75:213-218.

26 Nirde P, Georget V, Terouanne B, Galifer RB, Belon C, Sultan C: Quantitation of androgen receptor messenger RNA from genital skin fibroblasts by reverse transcription-competitive polymerase chain reaction. J Steroid Biochem Mol Biol 1998;66:35-43.

27 Castoria G, Lombardi M, Barone MV, Bilancio A, Di Domenico M, Bottero D, Vitale F, Migliaccio A, Auricchio F: Androgen-stimulated DNA synthesis and cytoskeletal changes in fibroblasts by a nontranscriptional receptor action. J Cell Biol 2003;161:547-556.

28 McPhaul MJ, Schweikert HU, Allman DR: Assessment of androgen receptor function in genital skin fibroblasts using a recombinant adenovirus to deliver an androgen-responsive reporter gene. J Clin Endocrinol Metab 1997; 82:1944-1948.

29 Bamberger CH, Else T, Bamberger AM, Beil UF, Schulte HM: Dissociative glucocorticoid activity of medroxyprogesterone acetate in normal human lymphocytes. J Clin Endocrinol Metab 1999;84:4055-4061.

30 Weidemann W, Linck B, Haupt H, Mentrup B, Romalo G, Stockklauser K, Brinkmann AO, Schweikert HU, Spindler KD: Clinical and biochemical investigations and molecular analysis of subjects with mutations in the androgen receptor gene. Clin Endocrinol 1996; 45:733-739.

-31 Ahmed SF, Cheng A, Dovey L, Hawkins JR, Martin H, Rowland J, Shimura N, Tait AD, Hughes IA: Phenotypic features, androgen receptor binding, and mutational analysis in 278 clinical cases reported as androgen insensitivity syndrome. J Clin Endocrinol Metab 2000; 85:658-665.

32 McPhaul MJ, Marcelli M, Zoppi S, Wilson CM, Griffin JE, Wilson JD: Mutations in the ligand-binding domain of the androgen receptor gene cluster in two regions of the gene. $\mathrm{J}$ Clin Invest 1992;90:2097-2101.

33 Hannema SE, Scott IS, Hodapp J, Martin H, Coleman N, Schwabe JW, Hughes IA: Residual activity of mutant androgen receptors explains Wolffian duct development in the complete androgen insensitivity syndrome. J Clin Endocrinol Metab 2004;89:5815-5822. 